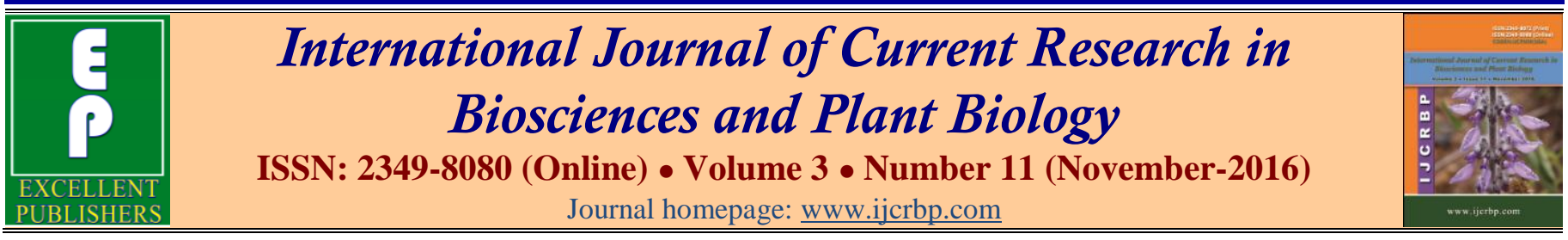

\title{
Analysis of Genetic Diversity of Dioscorea japonica Germplasm in China Using Inter-simple Sequence Repeat Markers
}

\author{
Jinping Wu, Zili Ding, Zhenbiao Jiao, Leifu Chen, Zhengming Qiu and Fengling Guo*
}

Hubei Academy of Agricultural Sciences, Wuhan 430064, China

*Corresponding author.

\begin{abstract}
A b stract
Yams (Dioscorea spp.) are widely cultivated in China, with many landraces maintained by local farmers. However, little is known about their diversity or species identity. In this study, inter-simple sequence repeats (ISSRs) were used to determine genetic diversity within 64 yam landraces from 12 provinces of China. A total of 45 bands were amplified with five ISSR primers, of which $40(88.89 \%)$ were polymorphic, suggesting a high level of polymorphism. Moreover, genetic diversity, estimated using Shannon' index, was 0.3702 , indicating relatively high genetic variation. A dendrogram of within-group linkage subsequently divided the 64 cultivars into three main clusters. Overall, the results suggest that these Chinese yam landraces are a valuable source of genes for future yam breeding programs.
\end{abstract}

\section{Article Info}

Accepted: 14 October 2016

Available Online: 06 November 2016

\section{Keywords}

Chinese yam

Dioscorea species

Genetic diversity

Inter-simple sequence repeats

\section{Introduction}

Yams (Dioscorea species, Dioscoraceae) are perennial plants with trailing rhizomes, an important food crop in Southeast Asia, West Africa and tropical America (Wu et al., 2014). Chinese yam (Dioscorea polystachya Turcz) has an edible tuber and is widely cultivated in temperate regions of China and Japan where it is also used in Chinese traditional medicine to promote health, strengthen stomach function and treat anorexia.

Yams are considerably diverse both at the inter- and intra-specific level (Okoli, 1988), and this diversity has been exploited for ongoing domestication of wild yams in tropical and subtropical countries (Dumont, 2000; Scarcelli et al., 2006). More than 600 species of yam (Dioscorea spp.) are known worldwide, 93 of which are found in China (Zhou et al., 2008) making it an important area of yam domestication (Coursey, 1967; Zhou et al., 2008). A number of Dioscorea species have so far been domesticated and are widely cultivated for consumption and medicinal use. The numerous chemical components of Chinese yams such as mannan, allantoin, dopamine, batatasine, phytic acid, abscisin II, amino acids, glucoprotein, choline, ergosterol, campesterol, saponins, starch, non-starch polysaccharides and various minerals $(\mathrm{K}, \mathrm{S}, \mathrm{Ca}, \mathrm{Mg}$, $\mathrm{Fe}, \mathrm{Zn}, \mathrm{Cu}, \mathrm{Mn}$ ) (Shujun, et al., 2008) also mean they are an important Chinese export.

In yam cultivation and marketing, high stable yield of marketable tubers of acceptable quality is preferred; that is, a good dry matter content, cooking texture, taste, dormancy period and rate of enzymatic browning (Lin et al., 2008).

Numerous studies have therefore examined the detailed 
properties of yams (Lin et al., 2008; Shujun, et al., 2008); however, breeding and selection of cultivars with novel or improved characteristics remains limited due to inadequate characterization of traditional cultivars. Moreover, considerable linguistic variation exists in the nomenclature of yam cultivars, with different geographical localities having their own unique series of names for different cultivars, seriously hampering reliable identification.

DNA fingerprinting has become an important tool for cultivar identification in plant breeding and germplasm management. Molecular markers are now increasingly used for taxonomic classification of yams as well as phylogenetic studies, genetic linkage map construction, cultivar identification and diversity studies. Molecular methods such as Random Amplified Polymorphic DNA (RAPD), Restriction Fragment Length Polymorphism (RFLP), Amplified Fragment Length Polymorphism
(AFLP), Microsatellite or Simple Sequence Repeats (SSRs), and Inter-Simple Sequence Repeat (ISSRs) (Wilkin et al., 2005; Tamiru et al., 2007; Tostain et al., 2007; Sartie et al., 2012) have enabled detection of differences among yam cultivars previously considered similar based on morphological and isozyme markers, demonstrating their usefulness as discriminative tools (Dansi et al., 2000). However, little remains known about the genetics of Chinese yam.

The ISSR method is a quick and simple technique, and a powerful tool for analysis of genetic diversity. The principle of ISSR is shown in Fig 1. The primers used in ISSR-PCR are designed from dinucleotide or trinucleotide simple repeats. They are stable, reproducible and reliable, have a high polymorphism detection rate (Zietkiewicz et al., 1994; Gupta et al., 1994), give large numbers of fragments per primer, and have a relatively low running cost.
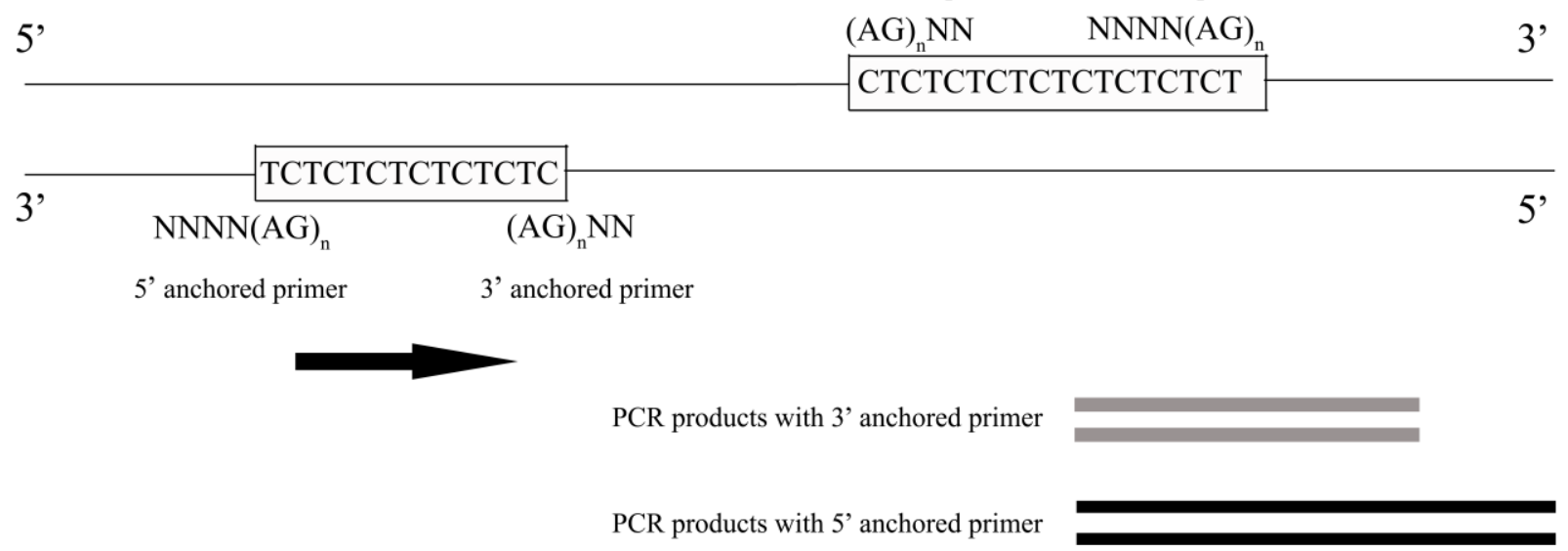

Fig. 1: Schematic representation of one of the primers, $(A G)_{8}$, used in ISSR-PCR. 3'-anchored and 5'-anchored targeting of a $(\mathrm{TC})_{n}$ repeat is shown.

ISSRs have been widely used for DNA fingerprinting, population genetics and phylogenetic studies in field crops, fruit trees and herbs, and to detect similarities between and within species (Zhou et al., 2004; Chtourou et al., 2016). Several genetic diversity studies based on ISSR markers have also been performed in Dioscorea, suggesting the power of ISSRs for analysis of yam genetic diversity (Wu et al., 2009; Nascimento et al., 2013). In this study, ISSRs were used to determine the level of genetic diversity among 64 cultivars of Dioscorea opposita Thunb., and the genetic relationships among different breeds in order to create a foundation for genetic analysis and breeding of Chinese yams.

\section{Materials and methods}

\section{Plant materials}

The production zone of yams in China is very widely distributed (Xu and Xu, 1997). In this study, a total of 64 yam landraces were collected from 12 provinces in China. Table 1 provides details on each landrace (species names, voucher numbers and population information). 
Table 1. The yam landraces and species used in this study.

\begin{tabular}{|c|c|c|c|}
\hline $\begin{array}{l}\text { Sample } \\
\text { number }\end{array}$ & Landrace & Species & Population \\
\hline 1 & Lichuanshanyao-1 & D. opposita & Tuanbao Town, Lichuan city, Hubei Province \\
\hline 2 & Huaishanyao & D. opposita & Jiaozuo City, Henan Province \\
\hline 3 & White shanyao & D. opposita & Anping County, Shijiazhuang, Hebei Province \\
\hline 4 & Shuangbaoshanyao & D. opposita & Jiangsu Province \\
\hline 5 & Lichuanshanyao-2 & D. opposita & Moudao Town, Lichuan city, Hubei Province \\
\hline 6 & Nongdaduanshanyao-1 & D. opposita & Shandong Province \\
\hline 7 & Zhucunshanyao & D. opposita & Zengcheng City, Guangzho, Guangdong Province \\
\hline 8 & Tiegunshanyao & D. opposita & Henan Province \\
\hline 9 & Zishanyao (Changsha) & D. opposita & Changshan City, Hunan Province \\
\hline 10 & Guilinshanyao & D. opposita & Guilin City, Guangxi Province \\
\hline 11 & Zishanyao (Shenzhen) & D. opposita & Shenzhen City, Guangdong Province \\
\hline 12 & Eshuyu & D. opposita & Shennongjia, Hubei Province \\
\hline 13 & Chuanlongshuyu & D. nipponica Makino & Shennongjia, Hubei Province \\
\hline 14 & Yeshanyao (Shennongjia) & D. japonica Thunb. & Shennongjia, Hubei Province \\
\hline 15 & Yeshanyao (Wuxue) & D. japonica Thunb. & Wuxue City, Hubei Province \\
\hline 16 & Ruichangshanyao & D. alata L. f.flabella Makino & Ruichang City, Jiangxi Province \\
\hline 17 & Zishanyao (Huangyan) & D. alata & Huangyan district, Taizhou City, Zhejiang Province \\
\hline 18 & Zishanyao (Yichun) & D. alata & Yichun City, Jiangxi Province \\
\hline 19 & Meizhoushanyao & D. alata & Meizhou City, Guangzhou, Guangdong Province \\
\hline 20 & Ximaoshanyao & D. opposita & Guangdong Province \\
\hline 21 & Mashanyao & D. opposita & Hebei Province \\
\hline 22 & Tieguanshanyao & D. opposita & Shandong Province \\
\hline 23 & Changshanyao & D. opposita & Shandong Province \\
\hline 24 & Duanshaoyao-1 (Shangdong) & D. opposita & Shandong Province \\
\hline 25 & Zishanyao (Meizhou) & D. alata & Meizhou City, Guangzhou, Guangdong Province \\
\hline 26 & Baishanyao (Meizhou) & D. alata & Meizhou City, Guangzhou, Guangdong Province \\
\hline 27 & Beihaishanyao & D. opposita & Beihai City, Guangxi Province \\
\hline 28 & Tongchengshanyao & D. opposita & Tongcheng City, Anhui Province \\
\hline 29 & Zishanyao (Guangxi) & D. alata & Guangxi Province \\
\hline 30 & Duanshanyao-2 (Shandong) & D. opposita & Shandong Province \\
\hline 31 & Shuangbaoshanyao (Shandong) & D. opposita & Shandong Province \\
\hline 32 & Maomingdashu & D. alata $\mathrm{L}$. & Maoming City, Guangdong Province \\
\hline 33 & Wuxueshanyao-1 & D. alata L. f.flabella Makino & Wuxue City, Hubei Province \\
\hline 34 & Jiaobanshanyao & D. alata L. f.flabella Makino & Enshi City, Hubei Province \\
\hline 35 & Yeshanyao (Yunnan) & D. japonica Thunb. & Yunnan Province \\
\hline 36 & Xiayeshanyao & $\begin{array}{l}\text { D. japonica Thunb. var. } \\
\text { oldhamii Uline et. Knuth }\end{array}$ & Shennongjia, Hubei Province \\
\hline 37 & Zishanyao (Taizhou) & D. alata & Taizhou City, Zhejiang Province \\
\hline 38 & Changyangshanyao & D. alata L. f.flabella Makino & Changyang City, Hubei Province \\
\hline 39 & Tuanjiezhenshanyao & D. opposita & Xishan district, Kunming City, Yunnan Province \\
\hline 40 & Wuxuehuangdu & D. bulbifera Linn. & Wuxue City, Hubei Province \\
\hline 41 & Xinyangshanyao & D. opposita & Xinyang City, Henan Province \\
\hline 42 & Xiaoyedun yeshanyao & D. japonica Thunb. & Wuxue City, Hubei Province \\
\hline 43 & Dazhoushanyao & D. opposita & Dazhou City, Sichuan Province \\
\hline
\end{tabular}




\begin{tabular}{|c|c|c|c|}
\hline $\begin{array}{l}\text { Sample } \\
\text { number }\end{array}$ & Landrace & Species & Population \\
\hline 44 & Bangbangshanyao & D. opposita & Enshi City, Hubei Province \\
\hline 45 & Baodingshanyao & D. opposita & Baoding City, Hebei Province \\
\hline 46 & Lichuanshanyao-3 & D. opposita & Tuanbao Town, Lichuan city, Hubei Province \\
\hline 47 & Wuxueshanyao-2 & D. alata L. f.flabella Makino & Wuxue City, Hubei Province \\
\hline 48 & Bangzhuangshanyao & D. alata L. f.flabella Makino & Wuxue City, Hubei Province \\
\hline 49 & Zhangzhuangshanyao & D. alata L.f.flabella Makino & Wuxue City, Hubei Province \\
\hline 50 & Tiegunshanyao (Henan) & D. opposita & Henan Province \\
\hline 51 & Xiangyangshanyao & D. opposita & Xiangyang City, Hubei Province \\
\hline 52 & Weifangshanyao & D. opposita & Weifang City, Shandong Province \\
\hline 53 & Huaianshanyao & D. opposita & Huaian City, Jiangsu Province \\
\hline 54 & Dujiawan-1 & D. opposita & Dujiawan, shiyan City, Hubei Province \\
\hline 55 & Dujiawan-2 & D. opposita & Dujiawan, shiyan City, Hubei Province \\
\hline 56 & Dujiawan-3 & D. opposita & Dujiawan, shiyan City, Hubei Province \\
\hline 57 & Dujiawan-4 & D. opposita & Dujiawan, shiyan City, Hubei Province \\
\hline 58 & Dujiawan-5 & D. opposita & Dujiawan, shiyan City, Hubei Province \\
\hline 59 & Dujiawan-6 & D. alata L. fflabella Makino & Dujiawan, shiyan City, Hubei Province \\
\hline 60 & Dujiawan-7 & D. opposita & Dujiawan, shiyan City, Hubei Province \\
\hline 61 & Fenghuangshan-1 & D. opposita & Fenghuangshan, shiyan City, Hubei Province \\
\hline 62 & Fenghuangshan-2 & D. opposita & Fenghuangshan, shiyan City, Hubei Province \\
\hline 63 & Fenghuangshan-3 & D. opposita & Fenghuangshan, shiyan City, Hubei Province \\
\hline 64 & Fenghuangshan-4 & D. opposita & Fenghuangshan, shiyan City, Hubei Province \\
\hline
\end{tabular}

\section{DNA extraction}

A 5g sample of young green leaves was collected from each landrace. The samples were then dried with silica gel and used for DNA extraction according to the improved cetyl trimethylammonium bromide (CTAB) method (Hamrick and Godt, 1989). All DNA samples were quantified by electrophoresis on $0.8 \%$ agarose gel and the concentration of DNA measured using the A260/A280 ratio. The DNA samples were then adjusted to a final concentration of $20 \mathrm{ng} / \mu \mathrm{l}$ for PCR amplification.

\section{ISSR-PCR conditions}

A total of 15 ISSR primers were screened using some of the DNA samples. PCR amplification was performed in a 9700 PE thermocycler (Applied Biosystems, Warrington, UK) with a total reaction volume of $25 \mu \mathrm{L}$ containing approximately $60 \mathrm{ng}$ of template DNA, $200 \mathrm{mM}$ of dNTP, $3 \mathrm{mM}$ of $\mathrm{MgCl}_{2}, 60 \mathrm{pg}$ of primers, $2.5 \mu \mathrm{L} 10 \times$ Taq DNA polymerase buffer, $2 \%$ deionization formamide and $1.5 \mathrm{U}$ Taq DNA polymerase. PCR amplification was carried out for $5 \mathrm{~min}$ at $94^{\circ} \mathrm{C}$ followed by 45 cycles of $60 \mathrm{~s}$ at $94^{\circ} \mathrm{C}, 45 \mathrm{~s}$ at $53^{\circ} \mathrm{C}$, and $90 \mathrm{~s}$ at $72^{\circ} \mathrm{C}$, ending with final extension for $7 \mathrm{~min}$ at $72{ }^{\circ} \mathrm{C}$.
Amplification was performed twice and only clear repetitive DNA bands utilized in ISSR analysis.

\section{Electrophoresis and analysis of the amplification products}

The amplification products were detected by electrophoresis on $1.7 \%$ agarose gel in $0.5 \times$ TAE buffer $(\mathrm{pH}$ 8.3) then stained with ethidium bromide (Zhou et al., 2004). The gels were photographed using an Alpha Innotech Ultraviolet MultiImage Light Cabinet (Alpha, US). A total of five ISSR primers produced clear and reproducible bands, and were subsequently selected for amplification. Amplified products were scored as present (1) or absent (0) to give a binary matrix. The computer software SPSS 20.0 was used to generate Jaccard's genetic similarity matrix using the Jaccard method, and a dendrogram showing within-group linkage obtained.

\section{Results}

\section{Identification of polymorphisms with the ISSR markers}

A total of five ISSR primers that produced clear and reproducible bands were selected for amplification of DNA samples from the 64 yam cultivars. A total of 45 
fragments were subsequently amplified, with an average of nine bands per primer. Of these, 40 were polymorphic. Fig. 2 shows gel electrophoresis patterns obtained using the primer $(\mathrm{CA})_{8} \mathrm{RG}$. The oligonucleotide sequences of the primers and resultant multiple band patterns are summarized in Table 2.

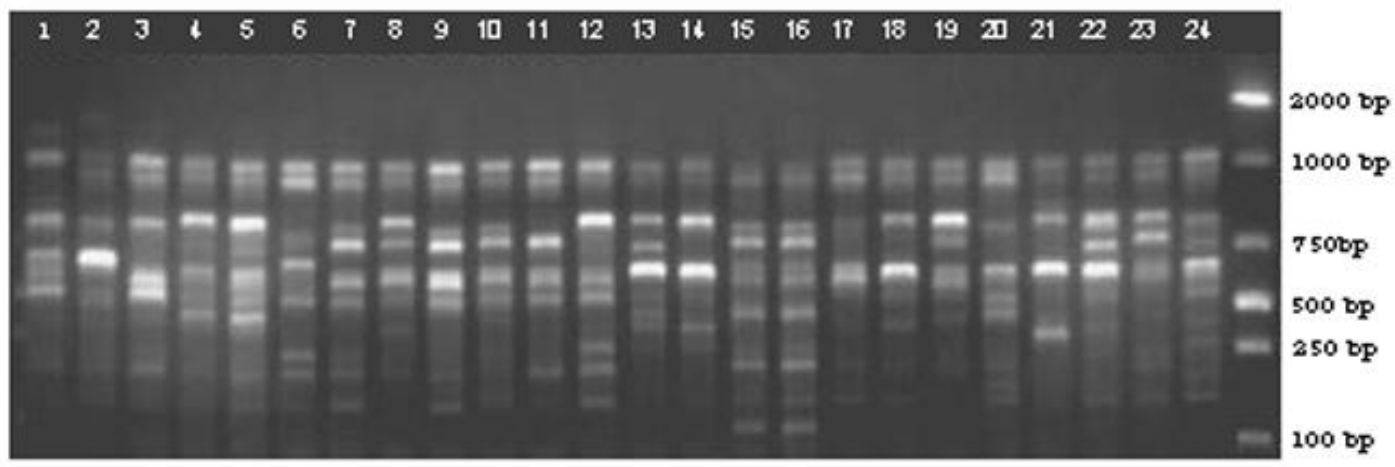

Fig. 2: ISSR patterns of Dioscorea opposita Thunb. generated using primer ISSR 4. Lanes 1 - 24 represent the No. 1 to No. 24 yam cultivar in Table 1 .

\section{Genetic diversity within the yam cultivars}

As shown in Table 2, the percentage of polymorphic bands (PPBs) ranged from 77.78 to $100 \%$, with a mean of $88.89 \%$ and eight polymorphic bands per primer. The
PPBs suggest that the ISSRs were polymorphic markers, suitable for detection of genetic diversity in these 64 cultivars of Chinese yam at the DNA level. The overall Shannon index was relatively high (0.3702), indicating relatively high genetic diversity.

Table 2. ISSR primers and parameters used to determine genetic diversity within 64 yam cultivars.

\begin{tabular}{lllllll}
\hline Primer & $\begin{array}{l}\text { Sequence } \\
\left(\mathbf{5}^{\prime}-\mathbf{3}^{\prime}\right)\end{array}$ & $\begin{array}{l}\text { Annealing } \\
\text { temperature }\left({ }^{\circ} \mathrm{C}\right)\end{array}$ & $\begin{array}{l}\text { No. of } \\
\text { bands }\end{array}$ & $\begin{array}{l}\text { No. of } \\
\text { polymorphisms }\end{array}$ & $\begin{array}{l}\text { Rate of } \\
\text { polymorphisms }\end{array}$ & $\begin{array}{l}\text { Shannon } \\
\text { Index }\end{array}$ \\
\hline ISSR1 & CCA(GTG $)_{4}$ & 53 & 9 & 7 & $77.78 \%$ & $100 \%$ \\
ISSR2 & $(\mathrm{CA})_{8}$ RG & 55 & 12 & 12 & $88.89 \%$ & \\
ISSR3 & $(\mathrm{AG})_{8} \mathrm{G}$ & 53 & 9 & 8 & $87.5 \%$ & \\
ISSR4 & $(\mathrm{AC})_{8} \mathrm{C}$ & 50 & 8 & 7 & $85.71 \%$ & 0.3702 \\
ISSR5 & $\mathrm{GGA}^{(G T G} \mathrm{GT}_{4}$ & 55 & 7 & 6 & $88.89 \%$ & \\
Total & & & 45 & 40 & & \\
\hline
\end{tabular}

$\mathrm{R}=\mathrm{A}, \mathrm{G}$

\section{Genetic relationships among the yam cultivars}

Based on the genetic similarity index, the cultivars were subsequently divided into three distinct groups (Fig. 3). Group I was composed of 39 cultivars of D. opposita and Group II of 9 varieties of D. opposita, D. bulbifera and D. japonica. Group III was composed of the remaining 16 accessions of $D$. alata. These large groups therefore consisted of a mixture of accessions from different geographical regions, indicating the distribution of highly related accessions within different regions.

\section{Discussion}

Evaluation and identification of germplasms using ISSR markers plays an important role in studies of genetics and breeding. In this study, five ISSR primers were used to fingerprint and determine genetic diversity within 64 yam cultivars. Using these primers, 45 discernible DNA fragments were generated, of which 40 were polymorphic, suggesting relatively high polymorphisms $(88.9 \%)$ in the yam cultivars based on statistical data. A high rate of polymorphisms is common in ISSR-amplified products, suggesting that ISSR amplification is a useful and potentially powerful technique for genotypic studies of yams at the species level. In general, Chinese yams have lower genetic diversity than more widespread species. Factors such as geographical range, the number of endemic species, breeding systems, vegetative reproduction and dispersal patterns significantly influence the genetic diversity of a species. In our study, the level of genetic diversity was relatively high (Shannon index: $\mathrm{I}=$ 0.3702) among the Chinese yam cultivars compared to that of perennial herbs (0.116) (Hamrick and Godt, 1989). 


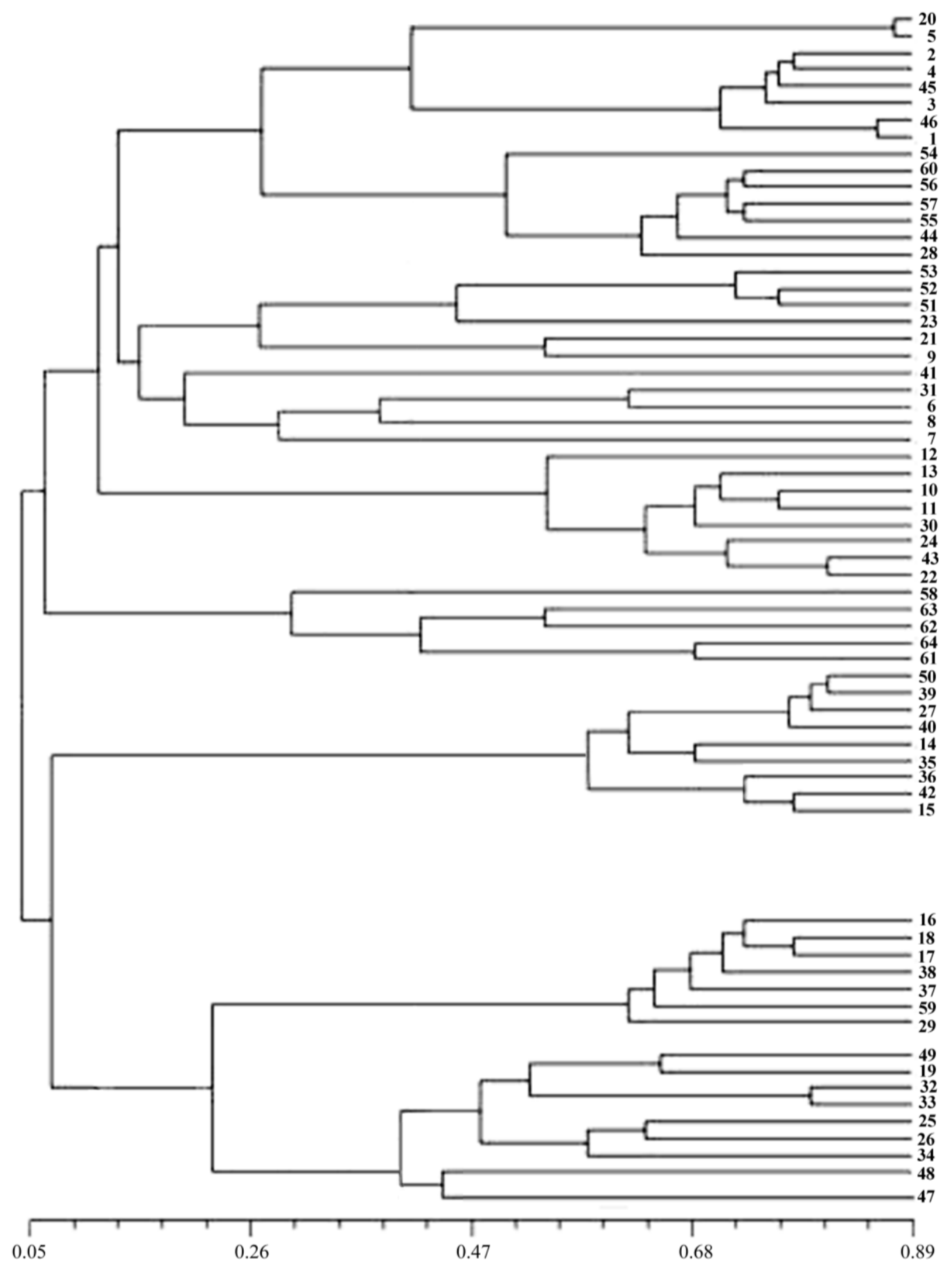

Fig. 3: UPGMA dendrogram of the 64 landraces of Chinese yam obtained based on ISSR markers. Landraces corresponding to each number are detailed in Table 1.

However, the dendrogram consisted of only three groups. Cluster I was composed of 39 cultivars of D. opposita including Huaishanyao and White Shanyao, while 16 cultivars of $D$. alata formed Cluster III. Meanwhile, Cluster II consisted of nine cultivars including Beihaishanyao, Wuxuehuangdu and Yeshanyao (Yunnan), which belong to the species D. opposita,
D. bulbifera and D. japonica respectively, which were possibly the result of crossing between parent species.

\section{Conclusion}

In conclusion, the ISSR DNA markers used in this study revealed relatively high genetic diversity and 
phylogenetic relationships among 64 Chinese yam varieties. These results will help domestication of Chinese yams as well as the development of yam germplasm in China.

\section{Conflict of interest statement}

Authors declare that they have no conflict of interest.

\section{References}

Chtourou-Ghorbel, N., Mheni, N.B., Elazreg, H., et al., 2016. Genetic diversity in Tunisian perennial forage grasses revealed by inter-simple sequence repeats markers. Biochem. Systemat. Ecol. 66, 154-160.

Coursey, D.G., 1967. Yams: An account of the nature, origins, cultivation and utilisation of the useful members of the Dioscoreaceae. Published by Longmans, Green and Co.

Dansi, A., Mignouna, H.D., Zoundjihékpon, J., Sangare, A., Ahoussou, N., Asiedu, R., 2000. Identification of some Benin Republic's Guinea yam (Dioscorea cayenensis/ Dioscorea rotundata complex) cultivars using randomly amplified polymorphic DNA. Genet. Resour. Crop Evol. 47(6), 619-625.

Dumont, R.P., 2000. Domestication of yams (Dioscorea cayenensis-rotundata) within the Bariba ethnic group in Benin. Outlook Agric. 29, 137-143.

Gupta, M., Chyi, Y. S., Romero-Severson, J., Owen, J. L.., 1994. Amplification of DNA markers from evolutionarily diverse genomes using single primers of simple-sequence repeats. Theor. Appl. Genet. 89(7-8), 998-1006.

Hamrick, J. L., Godt, M. J. W., 1989. Allozyme diversity in plant species. In: Plant Population Genetics, Breeding and Genetic Resources (Eds.: Brown, A. H. D., Clegg, M. T., Kahler, A.L., Weir, B.S.). Sinauer Associates, Sunderland, MA. pp.43-63.

Lin, J.T., Yang, D. J., 2008. Determination of steroidal saponins in different organs of yam (Dioscorea pseudojaponica Yamamoto). Food Chem. 108(3), 10681074.

Nascimento, W.F., Rodrigues, J.F., Koehler, S., Gepts, P., Veasey, E. A., 2013. Spatially structured genetic diversity of the Amerindian yam (Dioscorea trifida L.) assessed by SSR and ISSR markers in Southern Brazil. Genet. Resour. Crop Evol. 60(8), 2405-2420.

Okoli, O.O., 1988. Yam germplasm diversity, uses and prospects for crop improvement in Africa. International Conference on Crop Genetic Resources of Africa. Ibadan (Nigeria). 17-20 Oct 1988.
Sartie, A., Asiedu, R., Franco, J., 2012. Genetic and phenotypic diversity in a germplasm working collection of cultivated tropical yams (Dioscorea spp.). Genet. Resour. Crop Evol. 59(8), 1753-1765.

Scarcelli, N., Tostain, S., Mariac, C., Agbangla. C., Da, O., Berthaud, J., Pham, J.-L., 2006. Genetic nature of yams (Dioscorea sp.) domesticated by farmers in Benin (West Africa). Genet. Resour. Crop Evol. 53(1), 121-130.

Shujun, W., Jinglin, Y., Hongyan, L., Weiping, C., 2008. Characterisation and preliminary lipid-lowering evaluation of starch from Chinese yam. Food Chem. 108(1), 176-181.

Tamiru, M., Becker, H.C., Maass, B.L., 2007. Genetic diversity in yam germplasm from Ethiopia and their relatedness to the main cultivated species assessed by AFLP markers. Crop Sci. 47(4), 1744-1753.

Tostain, S., Agbangla, C., Scarcelli, N., Mariac, C., Daïnou, O., Berthaud, J., Pham, J.-L., 2007. Genetic diversity analysis of yam cultivars (Dioscorea rotundata Poir.) in Benin using simple sequence repeat (SSR) markers. Plant Genet. Resour. 5(2), 71-81.

Wilkin, P., Schols, P., Chase, M. W., Chayamarit, K., Furness, C. A., Huysmans, S., Rakotonasolo, F., Smets, E., Thapyai, C., 2005. A plastid gene phylogeny of the yam genus, Dioscorea: Roots, fruits and Madagascar. Syst. Bot. 30(4), 736-749.

Wu, Z.G., Li, X.X., Lin, X.C., Jiang, W., Tao, Z. M., Mantri, N., Fan, C. Y., Bao, X. Q., 2014. Genetic diversity analysis of yams (Dioscorea spp.) cultivated in China using ISSR and SRAP markers. Genet. Resour. Crop Evol. 61(3), 639-650.

Wu, Z. G., Leng, C. H., Tao, Z. M., Wei, Y. H., Jiang, C. X., 2009. Genetic diversity of Dioscorea alata based on ISSR analysis. China J. Chinese Materia Medica. 34(23), 30173020.

Xu, G.J., Xu, L.S., 1997. Species systematization and quality evaluation of commonly used Chinese traditional drugs, South-China. Vol. II. Fuzhou. pp.449-471.

Zhou, Y., Zhou, C., Yao, H., Liu, Y., Tu, R., 2008. Application of ISSR markers in detection of genetic variation among Chinese yam (Dioscorea opposita Thunb) cultivars. Life Sci. J. 5(4), 6-12.

Zhou, Y.Q., Jing, J.Z., Li, Z.Y., Zhang, B.H., Jia, J. F., 2004. Assessment of genetic diversity of Rehmannia glutinosa germplasm detected by RAPDs and ISSRs. Yi chuan= Hereditas/Zhongguo yi chuan xue hui bian ji, 26(6), 922-928.

Zietkiewicz, E., Rafalski, A., Labuda, D., 1994. Genome fingerprinting by simple sequence repeat (SSR)-anchored polymerase chain reaction amplification. Genomics. 20(2), 176-183.

\section{How to cite this article:}

Wu, J., Ding, Z., Jiao, Z., Chen, L., Qiu, Z., Guo, F., 2016. Analysis of genetic diversity of Dioscorea japonica germplasm in China using inter-simple sequence repeat markers. Int. J. Curr. Res. Biosci. Plant Biol. 3(11), 36-42. doi: http://dx.doi.org/10.20546/ijcrbp.2016.311.006 